\title{
Cigarette smoking and postmenopausal breast cancer risk in a prospective cohort
}

\author{
S J Nyante ${ }^{*}$, , G L Gierach ${ }^{1}$, C M Dallal ${ }^{2}$, N D Freedman ${ }^{1}$, Y Park ${ }^{1}$, K N Danforth ${ }^{3}$, A R Hollenbeck ${ }^{4}$ \\ and L A Brinton ${ }^{1}$
}

${ }^{1}$ Division of Cancer Epidemiology and Genetics, National Cancer Institute, 9609 Medical Center Drive, Bethesda, MD 20892, USA; ${ }^{2}$ Department of Epidemiology and Biostatistics, University of Maryland School of Public Health, 2234 SPH Building no. 255, College Park, MD 20742, USA; ${ }^{3}$ Department of Research and Evaluation, Kaiser Permanente Southern California, 100 South Los Robles Avenue, 2nd Floor, Pasadena, CA 91101, USA and ${ }^{4}$ Strategic Issues Research, AARP Research Center, 601 E Street NW, Washington, DC 20049, USA

Background: The relationship between cigarette smoking and breast cancer risk has been inconsistent, potentially due to modification by other factors or confounding.

Methods: We examined smoking and breast cancer risk in a prospective cohort of 186150 female AARP (formerly American Association of Retired Persons) members, ages 50-71 years, who joined the study in 1995-96 by responding to a questionnaire. Through 2006, 7481 breast cancers were diagnosed. Multivariable-adjusted hazard ratios (HRs) were estimated, overall and stratified by breast cancer risk factors, using Cox proportional hazards regression. Multiplicative interactions were evaluated using the likelihood ratio test.

Results: Increased breast cancer risk was associated with current (HR 1.19, 95\% confidence interval (CI) 1.10-1.28) and former ( $\mathrm{HR}$ 1.07, $\mathrm{Cl} 1.01-1.13)$ smoking. The current smoking association was stronger among women without ( $\mathrm{HR} 1.24, \mathrm{Cl} 1.15-1.35)$ as compared to those with a family history of breast cancer (HR 0.94, Cl 0.78-1.13) (P-interaction=0.03). The current smoking association was also stronger among those with later ( $\geqslant 15$ years: $\mathrm{HR} 1.52, \mathrm{Cl} 1.20-1.94)$ as compared with earlier ( $\leqslant 12$ years: HR $1.14, \mathrm{Cl} 1.03-1.27$; 13-14 years: $\mathrm{HR} 1.18, \mathrm{Cl} 1.05-1.32)$ ages at menarche $(P$-interaction $=0.03)$.

Conclusions: Risk was elevated in smokers, particularly in those without a family history or late menarche. Research into smoking's effects on the genome and breast development may clarify these relationships.

There is a growing body of evidence to suggest a relationship between cigarette smoking and increased breast cancer risk. Components of cigarette smoke have been detected in fluid from breast ducts of smokers (Petrakis et al, 1978; Hill and Wynder, 1979), and smoking has been associated with a higher level of DNA adducts (Perera et al, 1995; Li et al, 1996), higher prevalence of TP53 mutations and p53 overexpression in breast tumours (Gammon et al, 1999; Conway et al, 2002), providing a plausible hypothesis for a biological link between smoking and risk. Yet, epidemiologic evidence has been mixed. The majority of studies have used a case-control design and reported a mixture of positive, null, and inverse associations (Terry and Rohan, 2002). But as noted by Terry and Rohan (Terry and Rohan, 2002), case-control analyses of smoking may be subject to differential recall bias; prospective assessments of smoking avoid this bias and therefore may be more appropriate. While early prospective studies reported a mixture of positive (Hiatt and Fireman, 1986) and null (Hiatt et al, 1988; Schatzkin et al, 1989; Engeland et al, 1996; Nordlund et al, 1997) associations, more recent cohort studies have reported positive associations, with relative risks ranging from 1.08 to 1.70 for current smoking and 1.00 to 1.34 for former smoking (Manjer et al, 2001; Al-Delaimy et al, 2004; Reynolds et al, 2004; Gram et al, 2005; Hanaoka et al, 2005; Olson et al, 2005; Cui et al, 2006; Ha et al, 2007; Xue et al, 2011; Luo et al, 2011b; Gaudet et al, 2013).

Reasons for the variation in association among prospective studies are unclear, but potential causes include confounding or

*Correspondence: Dr SJ Nyante; E-mail: sarah.nyante@nih.gov

Received 23 October 2013; revised 3 February 2014; accepted 10 February 2014; published online 18 March 2014

(c) 2014 Cancer Research UK. All rights reserved 0007-0920/14 
effect measure modification. Most recent studies have adjusted for potential confounders in regression models, but it is possible that residual confounding could affect the association between smoking and risk (Hamajima et al, 2002). Alcohol use, in particular, has been identified as a potential source of residual confounding due to the positive correlation between alcohol use and smoking (Moore et $a l, 2005)$ and the association between alcohol and increased breast cancer risk (Hamajima et al, 2002; Dumitrescu and Shields, 2005). In a recent study, Gaudet et al (2013) presented associations stratified by alcohol use status (never, former, current) but did not include information on the amount of alcohol consumed. As such, it is unclear whether associations among current and former drinkers are subject to residual confounding by the amount of alcohol consumed.

Limited prospective data also suggest that there may be differences in smoking-associated risk according to body mass index (BMI) and family history of breast cancer. In one study, smoking was associated with increased risk in non-obese women while there was no association among obese women (Luo et al, 2011a). In another, smoking-associated risk was stronger among women without a family history of breast cancer when compared with women with a family history (Reynolds et al, 2004). However, there was no modification by BMI or family history in other studies (Gram et al, 2005; Cui et al, 2006; Gaudet et al, 2013). There are also data to suggest that the smoking association with risk is elevated among current and former alcohol drinkers but not among non-drinkers (London et al, 1989; Gaudet et al, 2013), but these differences were not statistically significant and other studies have found no modification by alcohol use (Gram et al, 2005; Cui et al, 2006). Analyses involving menopausal status (Reynolds et al, 2004; Gram et al, 2005; Cui et al, 2006), menopausal hormone therapy (MHT) use (Cui et al, 2006; Gaudet et al, 2013), age (Gram et al, 2005), age at menarche (Cui et al, 2006), parity (Gram et al, 2005; Cui et al, 2006), age at first birth (Gram et al, 2005), and benign breast disease (Cui et al, 2006) suggest that these factors do not modify the association between smoking and risk, but these factors have been examined in a limited number of studies.

To clarify our understanding of the relationship between smoking and breast cancer risk, we examined the association using data from the National Institutes of Health (NIH)-AARP Diet and Health Study, a large prospective cohort study that has previously demonstrated breast cancer risk relationships for a variety of factors that could potentially confound or modify associations with cigarette smoking (Ahn et al, 2007; Brinton et al, 2008; Lew et al, 2009; Nyante et al, 2013). Additionally, we examined whether smoking was related to the risk of specific subgroups of breast cancer, defined by disease stage at diagnosis, histology, hormone receptor expression, and tumour grade.

\section{MATERIALS AND METHODS}

Study population. The NIH-AARP Diet and Health Study has been described previously (Schatzkin et al, 2001). Briefly, in 1995-1996 a questionnaire regarding health and nutrition was sent to members of AARP (formerly American Association of Retired Persons) who were 50-71 years old and living in California, Florida, Louisiana, New Jersey, North Carolina, Pennsylvania, Atlanta, Georgia, and Detroit, Michigan. The study was approved by the Special Studies Institutional Review Board of the National Cancer Institute. Completion of the questionnaire implied informed consent.

Of 617119 questionnaires returned, 567169 were completed satisfactorily (Schatzkin et al, 2001). For this analysis, we excluded responses that were duplicates $(N=179)$ or completed by proxy $(N=15760)$. We also excluded respondents who were male $(N=325172)$, had prevalent cancer $(N=23961)$, moved from the study area or died before the questionnaire was returned $(N=592)$, were premenopausal or had unknown menopausal status $(N=9420)$, withdrew from the study $(N=9)$, or did not provide smoking information $(\mathrm{N}=5926)$, resulting in 186150 postmenopausal women in the analytic cohort (Figure 1).

Risk factors. At enrolment, participants were asked whether they had smoked $\geqslant 100$ cigarettes during their lifetime, whether they currently smoked, when they stopped smoking, and the number of cigarettes they usually smoked per day. Smoking status was defined as follows: participants who had not smoked $\geqslant 100$ cigarettes were classified as never smokers; participants who had smoked $\geqslant 100$ cigarettes and either currently smoked or quit within 1 year of enrolment were classified as current smokers; and participants who had smoked $\geqslant 100$ cigarettes but stopped smoking $>1$ year prior to study enrolment were classified as former smokers.

Type of menopause was determined from the reason menstrual periods stopped, whether the ovaries had been removed, and age at last menstrual period. MHT use was determined from questions regarding how long women used 'replacement hormones' and whether they were currently using hormones. Body mass index was calculated as weight (kilograms) divided by squared height (metres). Frequency of vigorous physical activity was defined by how often women participated in exercise, sports, or carrying heavy loads that increased sweating, breathing, or heart rate and lasted $\geqslant 20 \mathrm{~min}$. Alcohol use (grams per day) was estimated from the frequency and amount of beer, wine, and liquor consumed (Lew et al, 2009). Family history of breast cancer was based on history in a first-degree female relative. Other covariates included age at menarche, age at first birth, previous breast biopsy, education level, and race/ethnicity. Data were missing for $<5 \%$ of participants for all variables.

Cohort follow-up. Participants were followed for changes of address using data from the US Postal Service, other address update services, and participant updates. Vital status was

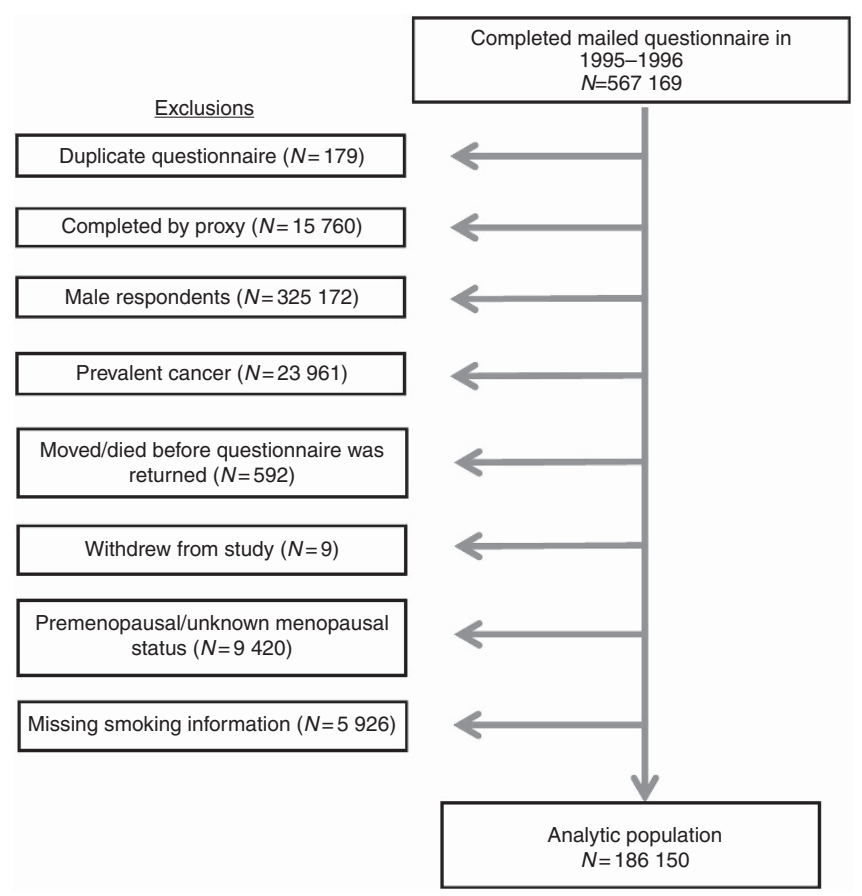

Figure 1. The relationship between smoking and breast cancer risk was examined in 186150 female, postmenopausal participants in the $\mathrm{NIH}-A A R P$ Diet and Health Study cohort. Exclusion criteria are shown in the figure. 
determined through periodic linkage to the Social Security Administration Death Master File, responses to study mailings, National Death Index searches, and cancer registry linkages. Follow-up time was calculated from the date the questionnaire was returned through the earliest of the following: breast cancer diagnosis, movement out of the registry ascertainment area, death, or 31 December 2006. 12790 (7\%) women moved from the registry ascertainment area prior to the end of follow-up; these women were younger and more educated than the rest of the cohort, but had similar distributions of smoking status and other risk factors.

Case ascertainment. Cancer diagnoses were obtained from state cancer registries in the eight study areas plus the adjacent states of Texas, Arizona, and Nevada (Michaud et al, 2005). A validation study comparing registry findings with self-reports and medical records estimated that linkage identified $90 \%$ of incident cancers (Michaud et al, 2005). Cases were defined as primary invasive breast cancers diagnosed after study enrolment. Histology, defined using the International Classification of Diseases for Oncology (Fritz et al, 2000), tumour grade, hormone receptor expression, and disease stage, defined by the Surveillance, Epidemiology, and End Results (SEER) Program summary staging definitions (Young et al, 2001), were obtained from cancer registry records. Disease stage at diagnosis was classified as localised if the disease was confined to the breast tissue and breast fat; regional spread if the disease had spread to adjacent tissues by direct extension and/or spread to the regional lymph nodes; or distant metastases if the disease had spread to non-adjacent organ sites. Hormone receptor data were reported by California, Louisiana, New Jersey, North Carolina, Arizona, Nevada, Georgia, and Michigan registries; these states ascertained $64 \%$ of the study's breast cancer cases.

Statistical analysis. Time-dependent interactions between each variable and age during follow-up were tested for significance to establish that hazards were proportional over time (all $P>0.05$ ). We estimated multivariable-adjusted hazard ratios (HR) and 95\% confidence intervals (CI) for the association between smoking status, number of cigarettes smoked, and time since quitting smoking and breast cancer risk using Cox proportional hazards regression in SAS v9.2 (SAS, Cary, NC, USA); age was the underlying timescale. Models were adjusted for age at enrolment (continuous), race/ethnicity (white non-Hispanic, other), education level (high school or less, vocational/some college, college graduate, postgraduate), age at menarche $(\leqslant 12,13-14, \geqslant 15$ years), age at first birth (nulliparous, <20, 20-24, 25-29, $\geqslant 30$ years), type of menopause (natural menopause at $<45,45-49$, $50-54, \geqslant 55$ years, bilateral oophorectomy, other surgery, medical/ unknown age at natural menopause), MHT use (never, former, current), BMI in quartiles $(<22.9,22.9-25.7,25.8-29.6$, $\left.>29.6 \mathrm{~kg} \mathrm{~m}^{-2}\right)$, alcohol consumption $(0,>0-5,>5-10$, $>10-20,>20-35,>35$ g per day), frequency of vigorous physical activity (never/rarely, 1-3 times per month, 1-2 times per week, 3-4 times per week, $\geqslant 5$ times per week), previous breast biopsy (no, yes), and family history of breast cancer (no, yes). To further evaluate confounding by the amount of alcohol consumed, we also estimated smoking associations within strata of alcohol consumption. Formal tests of linear trend for number of cigarettes and time since quitting were conducted by modelling exposure categories as ordinal variables among smokers only.

Effect measure modification by BMI $\left(<30, \geqslant 30 \mathrm{~kg} \mathrm{~m}^{-2}\right)$, family history of breast cancer (no, yes), alcohol consumption ( $\leqslant 5$ g per day, $>5 \mathrm{~g}$ per day), type of menopause (natural at $<50$ years, natural at $\geqslant 50$ years, bilateral oophorectomy, other surgical or medical menopause), MHT use (never, former, current), age at menarche ( $\leqslant 12,13-14, \geqslant 15$ years), age at first birth (nulliparous, $<25$, $\geqslant 25$ years), previous breast biopsy (yes, no), and age at baseline $(<55,55-59,60-64, \geqslant 65$ years) was evaluated using the same categorisations used in previous studies that reported interaction with these factors (Vatten and Kvinnsland, 1990; Ursin et al, 2005; Magnusson et al, 2007; Luo et al, 2011a) or categorisations associated with breast cancer risk. We also evaluated alternative categorisations for BMI and MHT using categorisations used in prior studies (BMI: $\leqslant 24,>24 \mathrm{~kg} \mathrm{~m}^{-2}$; MHT: never, ever) (Vatten and Kvinnsland, 1990; Ursin et al, 2005). We constructed risk estimates for smoking status stratified by these factors and additionally compared multivariable-adjusted models with and without multiplicative interaction terms using the likelihood ratio test. Tests were two-sided and $P$-values $<0.05$ were considered statistically significant. The expected joint HR under the multiplicative null was calculated by multiplying the HR associated with only smoking (unexposed to the potential modifier) and the HR associated with only being exposed to the potential modifier (unexposed to smoking).

Associations between smoking and risk were estimated for specific breast cancer types, defined by disease stage, histology, oestrogen and progesterone receptor (ER, PR) expression, and tumour grade. Tests of statistical heterogeneity among tumour types were performed using case-only logistic regression. Risk of ER/PR-defined tumours was evaluated using data only from participants that lived in states where registries collected hormone receptor data.

To evaluate whether the presence of smoking-related health conditions affected the relationship with risk, we examined models that excluded women with self-reported poor health or emphysema and compared those results to the main analysis. We also estimated associations for the first and second halves of the follow-up period to address the possibility that changes in health characteristics or behaviours during the follow-up period affected risk estimates. For the first half of follow-up, person-time was truncated 5 years after enrolment and cases occurring after that time were censored. For the second half of follow-up, only person-time and incident cases occurring $>5$ years after enrolment were analysed.

A subsequent questionnaire mailed in 2004-2006 obtained additional information, including the age when participants started smoking. Of 186150 women in the baseline cohort, 90950 (49\%) provided additional smoking information in 2004-2006. We attempted to explore whether age at smoking initiation was associated with risk in this sub-cohort of women, but found that the association between smoking status and risk in the subgroup was null, potentially due to limited follow-up, lack of power, or selection bias. Therefore, age at smoking initiation was not included in further analyses.

\section{RESULTS}

A total of 186150 women were followed for a mean of 9.6 years (standard deviation-2.5); 17\% were current smokers, 38\% were former smokers, and $45 \%$ had never smoked (Supplementary Table 1). A total of 7481 breast cancers were diagnosed during follow-up. Breast cancer risk was elevated among current and former smokers as compared with never smokers (current, HR 1.19, 95\% CI 1.10-1.28; former, HR 1.07, 95\% CI 1.01-1.13; Table 1). There was no clear dose-response relationship between number of cigarettes smoked per day and risk among current or former smokers, nor was there a dose-response trend with time since quitting. Risk for former smokers remained slightly elevated when compared with never smokers, even for those who quit $\geqslant 10$ years prior to baseline (HR 1.04, 95\% CI 0.98-1.11).

To explore whether associations between smoking status and risk might be due to confounding by alcohol consumption, we estimated associations within strata of alcohol consumption and found that the association remained elevated across strata (Supplementary Table 2). Notably, current smoking was suggestive 


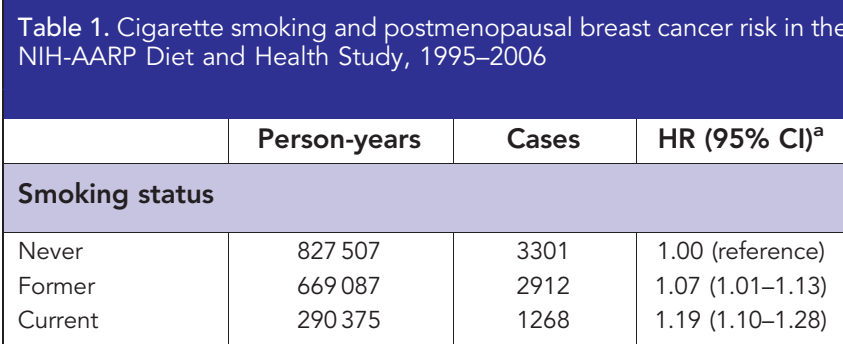

Cigarettes smoked per day

\begin{tabular}{|l|r|r|r|}
\hline Never & 827507 & 3301 & 1.00 (reference) \\
\hline \multicolumn{3}{|l|}{ Former smokers } \\
\hline $1-10$ & 258936 & 1105 & $1.07(0.99-1.15)$ \\
$11-20$ & 203078 & 830 & $1.00(0.92-1.08)$ \\
$21-30$ & 104912 & 498 & $1.18(1.07-1.31)$ \\
$31-40$ & 60464 & 295 & $1.19(1.05-1.35)$ \\
$\geqslant 41$ & 41697 & 184 & $1.05(0.89-1.23)$ \\
$P$-trend & & & 0.10 \\
\end{tabular}

\begin{tabular}{|l|r|r|c|}
\hline \multicolumn{3}{|l|}{ Current smokers } \\
\hline $1-10$ & 90146 & 394 & $1.19(1.06-1.34)$ \\
$11-20$ & 123196 & 556 & $1.22(1.11-1.35)$ \\
$21-30$ & 51707 & 210 & $1.06(0.91-1.23)$ \\
$31-40$ & 19946 & 88 & $1.12(0.88-1.41)$ \\
$\geqslant 41$ & 5379 & 20 & $0.92(0.57-1.49)$ \\
$P$-trend & & & 0.15 \\
\hline
\end{tabular}

Years since quit smoking ${ }^{b}$

\begin{tabular}{|l|c|c|c|}
\hline Never & 827507 & 3301 & 1.00 (reference) \\
$\geqslant 10$ & 472406 & 2058 & $1.04(0.98-1.11)$ \\
$5-9$ & 120876 & 543 & $1.19(1.08-1.31)$ \\
$1-4$ & 75805 & 311 & $1.09(0.96-1.24)$ \\
P-trend & & & 0.09 \\
\hline
\end{tabular}

Abbreviations: $\mathrm{Cl}=$ confidence interval; $\mathrm{HR}=$ hazard ratio.

${ }^{\text {a }}$ Adjusted for age at study entry, education level, race/ethnicity, age at menarche, nulliparity/age at first birth, type of and age at menopause, menopausal hormone therapy use, grams of alcohol per day, BMI, frequency of vigorous physical activity, previous breast biopsy, and family history of breast cancer.

$\mathbf{b}_{\text {Estimated among former and never smokers. }}$

of increased risk even among women who did not drink alcohol (HR 1.14, 95\% CI 0.98-1.32).

We next examined how the association between smoking status and risk varied across strata of other risk factors (Figure 2). The association between current smoking and risk was stronger among women with BMI $<30$, without a family history of breast cancer, who reached menarche at $\geqslant 15$ years old, who drank $\geqslant 5 \mathrm{~g}$ alcohol per day, who experienced natural menopause, who were not currently using menopausal hormones, and who were $<55$ years old at baseline. These differences were more pronounced for current rather than former smoking. With respect to alcohol consumption, smoking associations with risk did not differ when we separated the stratum of women who drank $\leqslant 5 \mathrm{~g}$ per day into $0 \mathrm{~g}$ and $>0$ to $5 \mathrm{~g}$ per day (Supplementary Table 2). Smokingassociated risks did not differ notably by age at first birth or previous breast biopsy (Figure 2). The results did not change when we used alternative categorisations for BMI $\left(\leqslant 24,>24 \mathrm{~kg} \mathrm{~m}^{-2}\right)$ or MHT use (never, ever) used in previous studies (Supplementary Table 3).

Tests of multiplicative interaction with smoking status were significant only for family history of breast cancer $(P$-interaction $=0.03)$ and age at menarche $(P$-interaction $=0.03)$. When we examined their joint associations with smoking, the increased risk due to current smoking among women with a family history (HR 1.49, CI 1.27-1.75) was lower than the expected joint association under the multiplicative null (expected $\mathrm{HR}=1.93$ ) (Table 2). The joint HR for former smokers was 1.60 (CI 1.45, 1.77), similar to the expected HR of 1.68 . With regards to the joint association between smoking and age at menarche, current smokers who reached menarche at $\geqslant 15$ years had 1.21 (95\% CI 0.99-1.47) times the risk of never smokers who reached menarche at $\leqslant 12$ years, an association that was qualitatively different from the expected joint HR of 0.88 (Table 3 ).

There were no strong differences when we examined risk of specific breast cancer types. Although current and former smoking were associated more strongly with distant metastases (current HR 2.05, CI 1.30-3.23; former HR 1.56, CI 1.06-2.30) than localised (current HR 1.21, CI 1.09-1.34; former HR 1.07, CI 0.99-1.16) or regional spread (current HR 1.18, CI 0.99-1.41; former HR 1.10, CI 0.96-1.26), these differences were not significantly different $(P$-heterogeneity $=0.22$; Table 4$)$. Associations with current, but not former, smoking were slightly stronger for lobular rather than ductal or mixed ductal-lobular tumours $(P$-heterogeneity $=0.55)$ and for $\mathrm{ER}+/ \mathrm{PR}-$ rather than $\mathrm{ER}+/ \mathrm{PR}+$ or $\mathrm{ER}-/ \mathrm{PR}-$ tumours $(P$-heterogeneity $=0.40)$. There were no differences in smoking-associated risk by tumour grade $(P$-heterogeneity $=0.90)$.

Associations between smoking status and risk were similar after excluding women who had emphysema or poor health, and also for the first and second halves of follow-up (Supplementary Table 4).

\section{DISCUSSION}

In the NIH-AARP Diet and Health study, current and former smokers had greater risk of breast cancer when compared with never smokers. Other cohort studies have shown similar associations between smoking and risk (Al-Delaimy et al, 2004; Reynolds et al, 2004; Gram et al, 2005; Hanaoka et al, 2005; Olson et al, 2005; Cui et al, 2006; Ha et al, 2007; Xue et al, 2011; Luo et al, 2011b; Gaudet et al, 2013), and a recent meta-analysis of prospective studies estimated combined hazard ratios of 1.12 for current smoking and 1.09 for former smoking (Gaudet et al, 2013). In our analysis, there was no dose-response with number of cigarettes smoked daily. Some (Reynolds et al, 2004; Gram et al, 2005; Cui et al, 2006; Xue et al, 2011) but not all (Al-Delaimy et al, 2004; Luo et al, 2011b; Gaudet et al, 2013) prior prospective studies have observed a positive trend between number of cigarettes and risk. While it is possible that the lack of a dose-response relationship in the NIH-AARP cohort could be due to the lack of a true association between smoking and breast cancer risk, this is unlikely given the consistency of associations for current and former smoking with those from previous prospective studies, including those that observed dose-response relationships with number of cigarettes smoked. Another possibility is that dose-response was not observed due to the small magnitude of the overall smoking association. Additionally, misclassification of the number of cigarettes smoked may have affected the results. Misclassification could have arisen due to improper recall of number of cigarettes smoked, the use of a single number to approximate dose when the number of cigarettes smoked daily may have varied over decades, or variation over time in cigarette brands, formulations, filters, and manufacturing processes that changed the dose of carcinogens ingested per day even if the same number of cigarettes was smoked per day. However, it is difficult to tell whether any of these reasons affected the associations we observed. The lack of association between time since quitting smoking and risk was similar to most previous prospective studies (Reynolds et al, 2004; Gram et al, 2005; Cui et al, 2006; Xue et al, 2011; Gaudet et al, 2013), except for one (Luo et al, 2011b) that observed lower risk as time since quitting increased. 
A

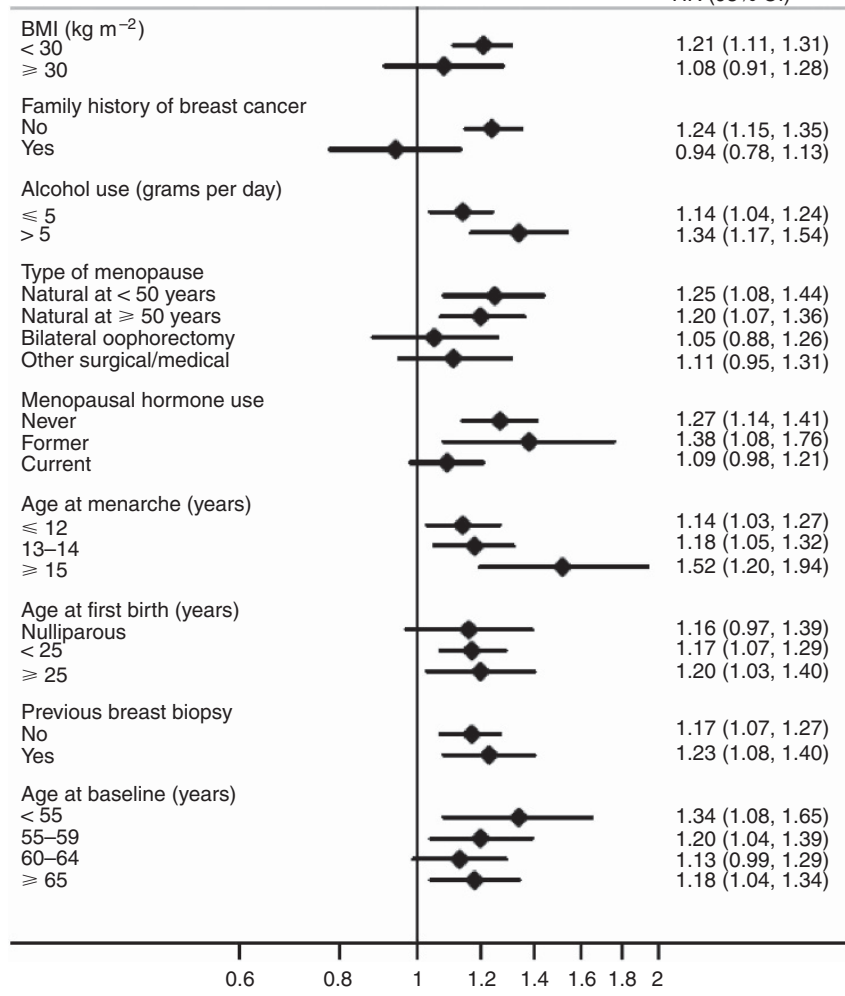

B BMI $\left(\mathrm{kg} \mathrm{m}^{-2}\right)$ $<30$ $\geqslant 30$

Family history of breast cancer No

Alcohol use (grams per day) $\leq 5$
$>5$

Type of menopause Natural at $<50$ years Natural at $\geqslant 50$ years Bilateral oophorears Bilateral oophorectomy

Menopausal hormone use

Never

Former

Current

Age at menarche (years)

$\leqslant 12$

13-14

$\geqslant 15$

Age at first birth (years) Nulliparous

$\geqslant 25$

Previous breast biopsy

No

Yes

Age at baseline (years)

$<55$

$55-59$

$\geq 65$
HR $(95 \% \mathrm{Cl}) \quad P$-int

$1.09(1.02,1.16) \quad 0.46$ $1.03(0.93,1.15)$

$1.08(1.02,1.15) \quad 0.03$ $1.02(0.90,1.16)$

$1.05(0.99,1.12) \quad 0.14$ $1.13(1.01,1.27)$

$1.04(0.92,1.17) \quad 0.55$ $1.12(1.03,1.22)$ $1.00(0.89,1.13)$

$1.10(1.01,1.20) \quad 0.37$ $1.07(0.89,1.30)$ $1.04(0.96,1.12)$

$1.07(0.99,1.16) \quad 0.03$ $1.02(0.94,1.11)$ $1.33(1.09,1.61)$

$1.16(1.02,1.33) \quad 0.09$ $1.00(0.93,1.07)$

$1.09(1.02,1.17) \quad 0.33$ $1.02(0.92,1.12)$

$1.19(0.99,1.43) \quad 0.91$ $1.01(0.90,1.14)$ $1.06(0.96,1.17)$

Figure 2. Association between smoking and postmenopausal breast cancer risk, stratified by breast cancer risk factors. The association between current (shown in A) and former (B) smoking and breast cancer risk, in comparison to never smoking, is shown stratified by known breast cancer risk factors. Associations were estimated using data from 186150 postmenopausal women in the NIH-AARP Diet and Health Study. The $P$-value for interaction ( $P$-int, at far right) was estimated using the likelihood ratio test by comparing models containing a multiplicative interaction term between smoking status (never, current, former) and the risk factor of interest with the models with no interaction term.

Table 2. Joint associations ${ }^{a}$ of smoking and family history of breast cancer with postmenopausal breast cancer risk

\begin{tabular}{|c|c|c|}
\hline & \multicolumn{2}{|c|}{ Family history of breast cancer } \\
\hline & No & Yes \\
\hline \multicolumn{3}{|c|}{ Smoking status } \\
\hline \multicolumn{3}{|l|}{ Never } \\
\hline $\begin{array}{l}\mathrm{HR}(95 \% \mathrm{Cl})^{\mathbf{b}} \\
\text { Cases } \\
\text { Person-years }\end{array}$ & $\begin{array}{c}1.00 \text { (reference) } \\
2551 \\
689876\end{array}$ & $\begin{array}{c}1.56(1.42-1.71) \\
617 \\
103053\end{array}$ \\
\hline \multicolumn{3}{|l|}{ Former } \\
\hline $\begin{array}{l}\mathrm{HR}(95 \% \mathrm{Cl})^{\mathbf{b}} \\
\text { Cases } \\
\text { Person-years }\end{array}$ & $\begin{array}{c}1.08(1.01-1.14) \\
2289 \\
558410\end{array}$ & $\begin{array}{c}1.60(1.45-1.77) \\
506 \\
83133\end{array}$ \\
\hline \multicolumn{3}{|l|}{ Current } \\
\hline $\begin{array}{l}\mathrm{HR}(95 \% \mathrm{Cl})^{\mathbf{b}} \\
\text { Cases } \\
\text { Person-years }\end{array}$ & $\begin{array}{c}1.24(1.14-1.34) \\
1023 \\
242761\end{array}$ & $\begin{array}{c}1.49(1.27-1.75) \\
174 \\
33628\end{array}$ \\
\hline \multicolumn{3}{|c|}{$\begin{array}{l}\text { Abbreviations: } \mathrm{Cl}=\text { confidence interval; } \mathrm{HR}=\text { hazard ratio. } \\
\text { a } P \text {-interaction }=0.03 \text {. } \\
{ }^{\text {b }} \text { Adjusted for age at study entry, education level, race/ethnicity, age at menarche, } \\
\text { nulliparity/age at first birth, age at and type of menopause, menopausal hormone therapy } \\
\text { use, grams of alcohol consumed per day, BMI, frequency of vigorous physical activity, and } \\
\text { previous breast biopsy. }\end{array}$} \\
\hline
\end{tabular}

Table 3. Joint associations ${ }^{a}$ of smoking and age at menarche with postmenopausal breast cancer risk

Age at menarche (years)

\begin{tabular}{l|l|l}
$\leqslant 12$ & $13-14$ & $\geqslant 15$
\end{tabular}

\section{Smoking status}

Never

\begin{tabular}{|l|c|c|c|}
\hline $\mathrm{HR}(95 \% \mathrm{Cl})^{\mathbf{b}}$ & 1.00 (reference) & $0.98(0.91-1.06)$ & $0.77(0.66-0.89)$ \\
Cases & 1665 & 1374 & 251 \\
Person-years & 401836 & 344288 & 78524 \\
\hline
\end{tabular}

\begin{tabular}{|l|c|c|c|}
\hline \multicolumn{4}{|l|}{ Former } \\
\hline $\begin{array}{l}\text { HR }(95 \% \mathrm{Cl})^{\mathbf{b}} \\
\text { Cases }\end{array}$ & $\begin{array}{c}1.07(0.99-1.15) \\
1456\end{array}$ & $\begin{array}{c}1.00(0.92-1.08) \\
1198\end{array}$ & $1.04(0.91-1.20)$ \\
Person-years & 326005 & 280890 & 60495 \\
\hline Current & \multicolumn{4}{|l|}{} \\
\hline HR (95\% Cl) & $1.14(1.03-1.27)$ & $1.15(1.03-1.28)$ & $1.21(0.99-1.47)$ \\
Cases & 620 & 515 & 131 \\
Person-years & 142563 & 118010 & 29113 \\
\hline
\end{tabular}

Abbreviations: $\mathrm{Cl}=$ confidence interval; $\mathrm{HR}=$ hazard ratio

${ }^{a} P$-interaction $=0.03$.

${ }^{\mathbf{b}}$ Adjusted for age at study entry, education level, race/ethnicity, nulliparity/age at first birth, age at and type of menopause, menopausal hormone therapy use, grams of alcohol consumed per day, BMI, frequency of vigorous physical activity, previous breast biopsy, and family history of breast cancer. 
Table 4. Smoking status and risk of specific breast cancer types in the NIH-AARP Diet and Health Study

\begin{tabular}{|c|c|c|c|c|}
\hline & Smoking status & Cases $(N)$ & $\mathrm{HR}(95 \% \mathrm{Cl})^{\mathrm{a}}$ & P-heterogeneity \\
\hline \multicolumn{5}{|c|}{ Disease stage at diagnosis } \\
\hline Localised & $\begin{array}{l}\text { Never } \\
\text { Former } \\
\text { Current }\end{array}$ & $\begin{array}{r}1571 \\
1404 \\
625\end{array}$ & $\begin{array}{l}1.00 \text { (reference) } \\
1.07(0.99-1.16) \\
1.21(1.09-1.34)\end{array}$ & 0.22 \\
\hline Regional spread & $\begin{array}{l}\text { Never } \\
\text { Former } \\
\text { Current }\end{array}$ & $\begin{array}{l}563 \\
496 \\
217\end{array}$ & $\begin{array}{l}1.00 \text { (reference) } \\
1.10(0.96-1.26) \\
1.18(0.99-1.41)\end{array}$ & \\
\hline Distant metastases & $\begin{array}{l}\text { Never } \\
\text { Former } \\
\text { Current }\end{array}$ & $\begin{array}{l}55 \\
67 \\
42\end{array}$ & $\begin{array}{l}1.00 \text { (reference) } \\
1.56(1.06-2.30) \\
2.05(1.30-3.23)\end{array}$ & \\
\hline \multicolumn{5}{|l|}{ Histology } \\
\hline Ductal & $\begin{array}{l}\text { Never } \\
\text { Former } \\
\text { Current }\end{array}$ & $\begin{array}{r}2272 \\
2147 \\
757\end{array}$ & $\begin{array}{l}1.00 \text { (reference) } \\
1.09(1.02-1.17) \\
1.17(1.07-1.28)\end{array}$ & 0.55 \\
\hline Lobular & $\begin{array}{l}\text { Never } \\
\text { Former } \\
\text { Current }\end{array}$ & $\begin{array}{l}357 \\
332 \\
130\end{array}$ & $\begin{array}{l}1.00 \text { (reference) } \\
1.05(0.89-1.24) \\
1.31(1.05-1.62)\end{array}$ & \\
\hline Mixed ductal-lobular & $\begin{array}{l}\text { Never } \\
\text { Former } \\
\text { Current }\end{array}$ & $\begin{array}{r}280 \\
252 \\
88\end{array}$ & $\begin{array}{l}1.00 \text { (reference) } \\
1.01(0.84-1.21) \\
1.03(0.79-1.35)\end{array}$ & \\
\hline \multicolumn{5}{|c|}{ Hormone receptor expression ${ }^{b, c}$} \\
\hline $\mathrm{ER}+/ \mathrm{PR}+$ & $\begin{array}{l}\text { Never } \\
\text { Former } \\
\text { Current }\end{array}$ & $\begin{array}{r}1148 \\
995 \\
369\end{array}$ & $\begin{array}{l}1.00 \text { (reference) } \\
1.04(0.95-1.14) \\
1.02(0.89-1.17)\end{array}$ & 0.40 \\
\hline$E R+/ P R-$ & $\begin{array}{l}\text { Never } \\
\text { Former } \\
\text { Current }\end{array}$ & $\begin{array}{l}222 \\
212 \\
109\end{array}$ & $\begin{array}{l}1.00 \text { (reference) } \\
1.13(0.92-1.39) \\
1.37(1.05-1.80)\end{array}$ & \\
\hline ER - /PR - & $\begin{array}{l}\text { Never } \\
\text { Former } \\
\text { Current }\end{array}$ & $\begin{array}{r}260 \\
219 \\
93\end{array}$ & $\begin{array}{l}1.00 \text { (reference) } \\
1.08(0.88-1.31) \\
1.05(0.81-1.38)\end{array}$ & \\
\hline \multicolumn{5}{|l|}{ Tumour grade } \\
\hline Low & $\begin{array}{l}\text { Never } \\
\text { Former } \\
\text { Current }\end{array}$ & $\begin{array}{l}675 \\
675 \\
236\end{array}$ & $\begin{array}{l}1.00 \text { (reference) } \\
1.12(0.99-1.25) \\
1.19(1.02-1.40)\end{array}$ & 0.90 \\
\hline Intermediate & $\begin{array}{l}\text { Never } \\
\text { Former } \\
\text { Current }\end{array}$ & $\begin{array}{r}1277 \\
1151 \\
408\end{array}$ & $\begin{array}{l}1.00 \text { (reference) } \\
1.03(0.95-1.13) \\
1.14(1.01-1.28)\end{array}$ & \\
\hline High & $\begin{array}{l}\text { Never } \\
\text { Former } \\
\text { Current } \\
\end{array}$ & $\begin{array}{l}868 \\
809 \\
293 \\
\end{array}$ & $\begin{array}{l}1.00 \text { (reference) } \\
1.10(0.99-1.22) \\
1.18(1.03-1.36)\end{array}$ & \\
\hline
\end{tabular}

Abbreviations: $\mathrm{Cl}=$ confidence interval; $\mathrm{HR}=$ hazard ratio

a Adjusted for age at study entry, education level, race/ethnicity, age at menarche, nulliparity/age at first birth, type of and age at menopause, menopausal hormone therapy use, grams of alcohol per day, BMI, frequency of vigorous physical activity, previous breast biopsy, and family history of breast cancer.

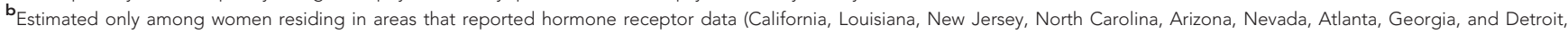
Michigan).

${ }^{c_{E}} \mathrm{R}-/ \mathrm{PR}+$ association not estimated due to low case numbers.

The association between smoking and risk is weak in comparison to other breast cancer risk factors, and previous investigations (Hamajima et al, 2002) have raised the suggestion that associations between smoking and risk may be due to confounding, in particular, due to alcohol consumption. Alcohol is a potentially strong confounder owing to its strong relationships with smoking (Moore et al, 2005) and breast cancer risk (Hamajima et al, 2002; Dumitrescu and Shields, 2005). In the NIH-AARP cohort, alcohol use was associated with risk in a doseresponse manner, such that women who drank $>35 \mathrm{~g}$ alcohol per day had 35\% greater risk than non-drinkers (Lew et al, 2009). Gaudet et al (2013) showed that the association between smoking and risk was unchanged after adjusting for recency of alcohol use (never, former, current use), but such broad categories leave potential for residual confounding by alcohol dose. In our analysis, the association between smoking and risk was still observed after adjusting for the amount of alcohol consumed. Further, we estimated associations within strata of alcohol use, with the hypothesis that if the association with smoking was due to confounding by increasing alcohol dose, associations within strata 
of alcohol use would be null. We found that risk associated with current smoking was elevated across all strata of alcohol use, but risk associated with former smoking was more variable. Together with the results from the study by Gaudet et al (2013), these results suggest that the association between smoking and risk is likely not due to confounding by alcohol. However, studies with sufficient data to simultaneously address issues of recency and dose of both smoking and alcohol use are needed to fully address this concern, particularly as it relates to former smoking and risk.

We evaluated interactions between smoking and a number of risk factors; many of the weaker variations in association may have been due to chance. Smoking-associated risks differed according to family history of breast cancer, where increased risks were only observed among women without a family history. This was consistent with the data from Reynolds et al (2004), who reported $39 \%$ increased risk for current smoking among postmenopausal women without a family history but no association among women with a family history. Two other studies did not find interaction between smoking and family history (Cui et al, 2006; Gaudet et al, 2013), but stratified estimates were not shown; therefore, it is unknown whether the estimates were consistent with our findings. In women at high risk of a specific type of familial breast cancer, BRCA1/BRCA2 mutation carriers, current smoking was not associated with increased risk (Ghadirian et al, 2004; Nkondjock et al, 2006; Ginsburg et al, 2009), which is consistent with our finding of no smoking-associated risk among women with a family history, although smoking was associated with increased risk among mutation carriers in one study (Breast Cancer Family Registry et al, 2008). The potential mechanism that would result in smoking-associated risk only among those without a family history of breast cancer is unknown. It could be hypothesised that smoking and familial breast cancer contribute to risk through the same pathway, and if that pathway is activated by factors related to family history there cannot be further activation by smoking. It is also possible that the differences we observed were due to chance. Greater exploration of the role of genetic factors in smokingassociated breast carcinogenesis is needed to understand possible effect modification by family history.

In this cohort, increased risk due to smoking was also higher among women with late ages at menarche, but there are scant data from other studies to support this result. Of the two previous prospective studies that examined smoking risks stratified by age at menarche, one (Gram et al, 2005) showed similar results-smoking was associated with increased risk among women who reached menarche at $\geqslant 13$ years but not women with menarche at $<13$ years. However, this was based on a small number of cases $(N=478)$ and may have been due to chance. Another study found no differences in smoking-associated risk by age at menarche (Cui et al, 2006).

Biologically, interaction between smoking and reproductive development is plausible. Pubertal breast development generally begins prior to menarche and marks a time of increased epithelial cell proliferation (Lanigan et al, 2007). As such, this may be a critical time for susceptibility to carcinogens. Other investigations point towards the importance of the timing of smoking initiation in relation to reproductive development. A recent meta-analysis reported positive associations between young age at smoking initiation and risk and smoking before first birth and risk (Gaudet et al, 2013). Studies have also reported that risk was elevated among women who started smoking prior to menarche (Gram et al, 2005; Gaudet et al, 2013), and that risk increased with the number of years of smoking between menarche and first birth (Xue et al, 2011).We were unable to evaluate the relationship between age at smoking initiation and risk in this cohort, or the effect of smoking initiation in relation to menarche or first birth. The relative importance of each reproductive milestone in relation to smoking and risk remains to be determined, but this and other studies to date indicate that smoking during these time periods may contribute to breast carcinogenesis. In both instances where we detected interaction, the increased risks were among subgroups that were at relatively lower risk (i.e., women without a family history of breast cancer and women with later age at menarche). It may be possible that increased risks due to smoking are more likely to be detected among women at low risk; however, this pattern was not consistent for all breast cancer risk factors in the stratified analyses.

There was little evidence to suggest that smoking was associated with risk of specific types of breast cancer, although risks were somewhat stronger for women with distant metastases, $\mathrm{ER}+/ \mathrm{PR}$ - tumours, and lobular breast tumours. Previous studies have been inconsistent, with several reporting stronger associations between smoking and ER + as compared with ER - tumours (Al-Delaimy et al, 2004; Luo et al, 2011b; Gaudet et al, 2013) and one reporting a strong positive association between smoking and ER - but not ER + tumours (Manjer et al, 2001). Studies that examined risk using combined ER/PR status found elevated risk of $\mathrm{ER}+/ \mathrm{PR}+$ (Luo et al, 2011b) and $\mathrm{ER}-/ \mathrm{PR}-($ Manjer et al, 2001) tumours, but not $\mathrm{ER}+/ \mathrm{PR}-$ tumours. Differences by disease stage and histology have been similarly inconsistent (Manjer et al, 2001; Luo et al, 2011b; Gaudet et al, 2013). Heterogeneity according to other tumour characteristics, such as molecular subtype, may exist. Studies with an emphasis on tissue collection are needed to investigate this possibility.

Our study was limited by the fact that smoking status and other covariates were assessed at baseline and do not account for changes during the follow-up period. Associations between smoking status and risk were similar when we compared the first 5 years of follow-up with the second 5 years, suggesting that changes that may have occurred during follow-up did not affect relative risks. In addition, information regarding passive smoking was not collected. Others have found that inclusion of passive smokers with never smokers yields a similar, if slightly attenuated, association (Egan et al, 2002; Reynolds et al, 2004; Luo et al, 2011b). Thus, if passive smoking affected this analysis it is likely that the association between active smoking and risk is stronger than what we reported here.

Smoking duration was not assessed on the baseline questionnaire and we were unable to evaluate whether breast cancer risk increased linearly with number of years of smoking, as has been reported by some studies (Gram et al, 2005; Olson et al, 2005; Cui et al, 2006; Luo et al, 2011b) but not others (Reynolds et al, 2004; Gaudet et al, 2013). Among previous studies that have evaluated both number of cigarettes (dose) and smoking duration, results for these exposures have been inconsistent: dose and duration trends were similar in four studies (Gram et al, 2005; Cui et al, 2006; Xue et al, 2011; Gaudet et al, 2013) and dissimilar in three (Al-Delaimy et al, 2004; Reynolds et al, 2004; Luo et al, $2011 b)$. Thus, we cannot infer from the lack of association with number of cigarettes smoked that there is also no association with duration in the NIH-AARP population. Hormone receptor status was only available for a subset of participants; thus, these analyses were less precise than those using the full cohort. Finally, we were unable to examine age at smoking initiation, which may be an important predictor of smoking-associated risk. Further examination of when women begin smoking, in concert with the timing of menarche and first birth, may provide insight as to the mechanism by which smoking is associated with breast cancer risk.

This study also had several strengths. Smoking was assessed prospectively, reducing the potential for recall bias. We used both adjustment and stratification to evaluate potential confounding by alcohol dose and found that neither approach was able to explain the smoking association with risk. This analysis included $>7000$ cases, more than most previous prospective studies of smoking and breast cancer risk, allowing for precise estimation of stratified associations and associations between smoking and specific breast 
cancer types. Finally, we conducted several sensitivity analyses to address potential biases due to women with poor health, respiratory diseases linked to smoking, or changes in risk factor status over the follow-up period. We found no evidence that these factors influenced the results.

\section{CONCLUSION}

Smoking status was positively associated with breast cancer risk in this cohort, but there was no dose-response trend with the number of cigarettes smoked per day or time since quitting. Risks were modified by family history of breast cancer and age at menarche, but additional research evaluating effects of smoking on the genome and on breast tissue during different stages of reproductive development are needed to better understand these findings.

\section{ACKNOWLEDGEMENTS}

This research was supported by the Intramural Research Program of the National Cancer Institute at the National Institutes of Health. Cancer incidence data from the Atlanta metropolitan area were collected by the Georgia Center for Cancer Statistics, Department of Epidemiology, Rollins School of Public Health, Emory University. Cancer incidence data from California were collected by the California Department of Health Services, Cancer Surveillance Section. Cancer incidence data from the Detroit metropolitan area were collected by the Michigan Cancer Surveillance Program, Community Health Administration, State of Michigan. The Florida cancer incidence data used in this report were collected by the Florida Cancer Data System (FCDC) under contract with the Florida Department of Health (FDOH).Cancer incidence data from Louisiana were collected by the Louisiana Tumour Registry, Louisiana State University Medical Center in New Orleans. Cancer incidence data from New Jersey were collected by the New Jersey State Cancer Registry, Cancer Epidemiology Services, New Jersey State Department of Health and Senior Services. Cancer incidence data from North Carolina were collected by the North Carolina Central Cancer Registry. Cancer incidence data from Pennsylvania were supplied by the Division of Health Statistics and Research, Pennsylvania Department of Health, Harrisburg, Pennsylvania. Cancer incidence data from Arizona were collected by the Arizona Cancer Registry, Division of Public Health Services, Arizona Department of Health Services. Cancer incidence data from Texas were collected by the Texas Cancer Registry, Cancer Epidemiology and Surveillance Branch, Texas Department of State Health Services. We are indebted to the participants in the NIH-AARP Diet and Health Study for their outstanding cooperation. We also thank Sigurd Hermansen and Kerry Grace Morrissey from Westat for study outcomes ascertainment and management and Leslie Carroll at Information Management Services for data support and analysis.

\section{CONFLICT OF INTEREST}

The authors declare no conflict of interest.

\section{DISCLAIMER}

The views expressed herein are solely those of the authors and do not necessarily reflect those of the FCDC or FDOH. The Pennsylvania Department of Health specifically disclaims responsibility for any analyses, interpretations or conclusions.

\section{REFERENCES}

Ahn J, Schatzkin A, Lacey Jr. JV, Albanes D, Ballard-Barbash R, Adams KF, Kipnis V, Mouw T, Hollenbeck AR, Leitzmann MF (2007) Adiposity, adult weight change, and postmenopausal breast cancer risk. Arch Intern Med 167(19): 2091-2102.

Al-Delaimy WK, Cho E, Chen WY, Colditz G, Willet WC (2004) A prospective study of smoking and risk of breast cancer in young adult women. Cancer Epidemiol Biomarkers Prev 13(3): 398-404.

Breast Cancer Family Registry, Kathleen Cuningham Consortium for Research into Familial Breast Cancer (Australasia), Ontario Cancer Genetics Network (Canada) (2008) Smoking and risk of breast cancer in carriers of mutations in BRCA1 or BRCA2 aged less than 50 years. Breast Cancer Res Treat 109(1): 67-75.

Brinton LA, Richesson D, Leitzmann MF, Gierach GL, Schatzkin A, Mouw T, Hollenbeck AR, Lacey JV Jr (2008) Menopausal hormone therapy and breast cancer risk in the NIH-AARP Diet and Health Study Cohort. Cancer Epidemiol Biomarkers Prev 17(11): 3150-3160.

Conway K, Edmiston SN, Cui L, Drouin SS, Pang J, He M, Tse CK, Geradts J, Dressler L, Liu ET, Millikan R, Newman B (2002) Prevalence and spectrum of $\mathrm{p} 53$ mutations associated with smoking in breast cancer. Cancer Res 62(7): 1987-1995.

Cui Y, Miller AB, Rohan TE (2006) Cigarette smoking and breast cancer risk: update of a prospective cohort study. Breast Cancer Res Treat 100(3): 293-299.

Dumitrescu RG, Shields PG (2005) The etiology of alcohol-induced breast cancer. Alcohol 35(3): 213-225.

Egan KM, Stampfer MJ, Hunter D, Hankinson S, Rosner BA, Holmes M, Willett WC, Colditz GA (2002) Active and passive smoking in breast cancer: prospective results from the Nurses' Health Study. Epidemiology 13(2): 138-145.

Engeland A, Andersen A, Haldorsen T, Tretli S (1996) Smoking habits and risk of cancers other than lung cancer: 28 years' follow-up of 26,000 Norwegian men and women. Cancer Causes Control 7(5): 497-506.

Fritz A, Percy C, Jack A, Shanmugaratnam K, Sobin L, Parkin D, Whelan S (2000) International Classification of Diseases for Oncology. (ICD-O-3) 3rd edn. World Health Organization: Geneva, Switzerland.

Gammon MD, Hibshoosh H, Terry MB, Bose S, Schoenberg JB, Brinton LA, Bernstein JL, Thompson WD (1999) Cigarette smoking and other risk factors in relation to p53 expression in breast cancer among young women. Cancer Epidemiol Biomarkers Prev 8(3): 255-263.

Gaudet MM, Gapstur SM, Sun J, Diver WR, Hannan LM, Thun MJ (2013) Active smoking and breast cancer risk: original cohort data and meta-analysis. J Natl Cancer Inst 105(8): 515-525.

Ghadirian P, Lubinski J, Lynch H, Neuhausen SL, Weber B, Isaacs C, Baruch RG, Randall S, Ainsworth P, Friedman E, Horsman D, Tonin P, Foulkes WD, Tung N, Sun P, Narod SA (2004) Smoking and the risk of breast cancer among carriers of BRCA mutations. Int J Cancer 110(3): $413-416$.

Ginsburg O, Ghadirian P, Lubinski J, Cybulski C, Lynch H, Neuhausen S, Kim-Sing C, Robson M, Domchek S, Isaacs C, Klijn J, Armel S, Foulkes WD, Tung N, Moller P, Sun P, Narod SA (2009) Smoking and the risk of breast cancer in BRCA1 and BRCA2 carriers: an update. Breast Cancer Res Treat 114(1): 127-135.

Gram IT, Braaten T, Terry PD, Sasco AJ, Adami HO, Lund E, Weiderpass E (2005) Breast cancer risk among women who start smoking as teenagers. Cancer Epidemiol Biomarkers Prev 14(1): 61-66.

Ha M, Mabuchi K, Sigurdson AJ, Freedman DM, Linet MS, Doody MM, Hauptmann M (2007) Smoking cigarettes before first childbirth and risk of breast cancer. Am J Epidemiol 166(1): 55-61.

Hamajima N, Hirose K, Tajima K, Rohan T, Calle EE, Heath Jr CW, Coates RJ, Liff JM, Talamini R, Chantarakul N, Koetsawang S, Rachawat D, Morabia A, Schuman L, Stewart W, Szklo M, Bain C, Schofield F, Siskind V, Band P, Coldman AJ, Gallagher RP, Hislop TG, Yang P, Kolonel LM, Nomura AM, Hu J, Johnson KC, Mao Y, De Sanjose S, Lee N, Marchbanks P, Ory HW, Peterson HB, Wilson HG, Wingo PA, Ebeling K, Kunde D, Nishan P, Hopper JL, Colditz G, Gajalanski V, Martin N, Pardthaisong T, Silpisornkosol S, Theetranont C, Boosiri B, Chutivongse S, Jimakorn P, Virutamasen P, Wongsrichanalai C, Ewertz M, Adami HO, Bergkvist L, Magnusson C, Persson I, Chang-Claude J, Paul C, Skegg DC, Spears GF, Boyle P, Evstifeeva T, Daling JR, Hutchinson WB, Malone K, Noonan EA, Stanford JL, 
Thomas DB, Weiss NS, White E, Andrieu N, Bremond A, Clavel F, Gairard B, Lansac J, Piana L, Renaud R, Izquierdo A, Viladiu P, Cuevas HR, Ontiveros P, Palet A, Salazar SB, Aristizabel N, Cuadros A, Tryggvadottir L, Tulinius H, Bachelot A, Le MG, Peto J, Franceschi S, Lubin F, Modan B, Ron E, Wax Y, Friedman GD, Hiatt RA, Levi F, Bishop T, Kosmelj K, Primic-Zakelj M, Ravnihar B, Stare J, Beeson WL, Fraser G, Bullbrook RD, Cuzick J, Duffy SW, Fentiman IS, Hayward JL, Wang DY, McMichael AJ, McPherson K, Hanson RL, Leske MC, Mahoney MC, Nasca PC, Varma AO, Weinstein AL, Moller TR, Olsson H, Ranstam J, Goldbohm RA, van den Brandt PA, Apelo RA, Baens J, de la Cruz JR, Javier B, Lacaya LB, Ngelangel CA, La Vecchia C, Negri E, Marubini E, Ferraroni M, Gerber M, Richardson S, Segala C, Gatei D, Kenya P, Kungu A, Mati JG, Brinton LA, Hoover R, Schairer C, Spirtas R, Lee HP, Rookus MA, van Leeuwen FE, Schoenberg JA, McCredie M, Gammon MD, Clarke EA, Jones L, Neil A, Vessey M, Yeates D, Appleby P, Banks E, Beral V, Bull D, Crossley B, Goodill A, Green J, Hermon C, Key T, Langston N, Lewis C, Reeves G, Collins R, Doll R, Peto R, Mabuchi K, Preston D, Hannaford P, Kay C, Rosero-Bixby L, Gao YT, Jin F, Yuan JM, Wei HY, Yun T, Zhiheng C, Berry G, Cooper Booth J, Jelihovsky T, MacLennan R, Shearman R, Wang QS, Baines CJ, Miller AB, Wall C, Lund E, Stalsberg H, Shu XO, Zheng W, Katsouyanni K, Trichopoulou A, Trichopoulos D, Dabancens A, Martinez L, Molina R, Salas O, Alexander FE, Anderson K, Folsom AR, Hulka BS, Bernstein L, Enger S, Haile RW, Paganini-Hill A, Pike MC, Ross RK, Ursin G, Yu MC, Longnecker MP, Newcomb P, Kalache A, Farley TM, Holck S, Meirik O (2002) Alcohol, tobacco and breast cancer-collaborative reanalysis of individual data from 53 epidemiological studies, including 58,515 women with breast cancer and 95,067 women without the disease. Br J Cancer 87(11): 1234-1245.

Hanaoka T, Yamamoto S, Sobue T, Sasaki S, Tsugane S (2005) Active and passive smoking and breast cancer risk in middle-aged Japanese women. Int J Cancer 114(2): 317-322.

Hiatt RA, Fireman BH (1986) Smoking, menopause, and breast cancer. J Natl Cancer Inst 76(5): 833-838.

Hiatt RA, Klatsky AL, Armstrong MA (1988) Alcohol consumption and the risk of breast cancer in a prepaid health plan. Cancer Res 48(8): 2284-2287.

Hill P, Wynder EL (1979) Nicotine and cotinine in breast fluid. Cancer Lett 6(4-5): 251-254.

Lanigan F, O'Connor D, Martin F, Gallagher WM (2007) Molecular links between mammary gland development and breast cancer. Cell Mol Life Sci 64(24): 3159-3184.

Lew JQ, Freedman ND, Leitzmann MF, Brinton LA, Hoover RN, Hollenbeck AR, Schatzkin A, Park Y (2009) Alcohol and risk of breast cancer by histologic type and hormone receptor status in postmenopausal women: the NIH-AARP Diet and Health Study. Am J Epidemiol 170(3): 308-317.

Li D, Wang M, Dhingra K, Hittelman WN (1996) Aromatic DNA adducts in adjacent tissues of breast cancer patients: clues to breast cancer etiology. Cancer Res 56(2): 287-293.

London SJ, Colditz GA, Stampfer MJ, Willett WC, Rosner BA, Speizer FE (1989) Prospective study of smoking and the risk of breast cancer. J Natl Cancer Inst 81(21): 1625-1631.

Luo J, Horn K, Ockene JK, Simon MS, Stefanick ML, Tong E, Margolis KL (2011a) Interaction between smoking and obesity and the risk of developing breast cancer among postmenopausal women: the Women's Health Initiative Observational Study. Am J Epidemiol 174(8): 919-928.

Luo J, Margolis KL, Wactawski-Wende J, Horn K, Messina C, Stefanick ML, Tindle HA, Tong E, Rohan TE (2011b) Association of active and passive smoking with risk of breast cancer among postmenopausal women: a prospective cohort study. BMJ 342: d1016.

Magnusson C, Wedren S, Rosenberg LU (2007) Cigarette smoking and breast cancer risk: a population-based study in Sweden. Br J Cancer 97(9): 1287-1290.
Manjer J, Malina J, Berglund G, Bondeson L, Garne JP, Janzon L (2001) Smoking associated with hormone receptor negative breast cancer. Int J Cancer 91(4): 580-584.

Michaud D, Midthune D, Hermansen S, Leitzmann M, Harlan L, Kipnis V, Schatzkin A (2005) Comparison of cancer registry case ascertainment with SEER estimates and self-reporting in a subset of the NIH-AARP Diet and Health Study. J Registry Manage 32(2): 70-75.

Moore AA, Gould R, Reuben DB, Greendale GA, Carter MK, Zhou K, Karlamangla A (2005) Longitudinal patterns and predictors of alcohol consumption in the United States. Am J Public Health 95(3): 458-465.

Nkondjock A, Robidoux A, Paredes Y, Narod SA, Ghadirian P (2006) Diet, lifestyle and BRCA-related breast cancer risk among French-Canadians. Breast Cancer Res Treat 98(3): 285-294.

Nordlund LA, Carstensen JM, Pershagen G (1997) Cancer incidence in female smokers: a 26-year follow-up. Int J Cancer 73(5): 625-628.

Nyante SJ, Dallal CM, Gierach GL, Park Y, Hollenbeck AR, Brinton LA (2013) Risk factors for specific histopathological types of postmenopausal breast cancer in the NIH-AARP Diet and Health Study. Am J Epidemiol 178(3): 359-371.

Olson JE, Vachon CM, Vierkant RA, Sweeney C, Limburg PJ, Cerhan JR, Sellers TA (2005) Prepregnancy exposure to cigarette smoking and subsequent risk of postmenopausal breast cancer. Mayo Clin Proc 80(11): 1423-1428.

Perera FP, Estabrook A, Hewer A, Channing K, Rundle A, Mooney LA, Whyatt R, Phillips DH (1995) Carcinogen-DNA adducts in human breast tissue. Cancer Epidemiol Biomarkers Prev 4(3): 233-238.

Petrakis NL, Gruenke LD, Beelen TC, Castagnoli Jr N, Craig JC (1978) Nicotine in breast fluid of nonlactating women. Science 199(4326): 303-305.

Reynolds P, Hurley S, Goldberg DE, Anton-Culver H, Bernstein L, Deapen D, Horn-Ross PL, Peel D, Pinder R, Ross RK, West D, Wright WE, Ziogas A (2004) Active smoking, household passive smoking, and breast cancer: evidence from the California Teachers Study. J Natl Cancer Inst 96(1): 29-37.

Schatzkin A, Carter CL, Green SB, Kreger BE, Splansky GL, Anderson KM, Helsel WE, Kannel WB (1989) Is alcohol consumption related to breast cancer? Results from the Framingham Heart Study. J Natl Cancer Inst 81(1): 31-35.

Schatzkin A, Subar AF, Thompson FE, Harlan LC, Tangrea J, Hollenbeck AR, Hurwitz PE, Coyle L, Schussler N, Michaud DS, Freedman LS, Brown CC, Midthune D, Kipnis V (2001) Design and serendipity in establishing a large cohort with wide dietary intake distributions: the National Institutes of Health-American Association of Retired Persons Diet and Health Study. Am J Epidemiol 154(12): 1119-1125.

Terry PD, Rohan TE (2002) Cigarette smoking and the risk of breast cancer in women: a review of the literature. Cancer Epidemiol Biomarkers Prev 11(10 Pt 1): 953-971.

Ursin G, Bernstein L, Lord SJ, Karim R, Deapen D, Press MF, Daling JR, Norman SA, Liff JM, Marchbanks PA, Folger SG, Simon MS, Strom BL, Burkman RT, Weiss LK, Spirtas R (2005) Reproductive factors and subtypes of breast cancer defined by hormone receptor and histology. Br J Cancer 93(3): 364-371.

Vatten LJ, Kvinnsland S (1990) Cigarette smoking and risk of breast cancer: a prospective study of 24,329 Norwegian women. Eur J Cancer 26(7): $830-833$.

Xue F, Willett WC, Rosner BA, Hankinson SE, Michels KB (2011) Cigarette smoking and the incidence of breast cancer. Arch Intern Med 171(2): 125-133.

Young Jr JL, Roffers SD, Ries LAG, Fritz AG, Hurlbut AA (eds) (2001) SEER Summary Staging Manual - 2000: Codes and Coding Instructions. National Cancer Institute: Bethesda, MD, NIH Pub. No. 01-4969).

This work is published under the standard license to publish agreement. After 12 months the work will become freely available and the license terms will switch to a Creative Commons AttributionNonCommercial-Share Alike 3.0 Unported License.

Supplementary Information accompanies this paper on British Journal of Cancer website (http://www.nature.com/bjc) 